\title{
Formation of Amides from Imines via Cyanide-Mediated Metal-Free Aerobic Oxidation
}

\author{
Hong-Ahn Seo ${ }^{\ddagger}$ Yeon-Ho Cho ${ }^{\ddagger}$ Ye-Sol Lee, and Cheol-Hong Cheon* \\ Department of Chemistry, Korea University, 145 Anam-ro, Seungbuk-gu, Seoul 02841, Republic of Korea
}




\section{NMR Spectra of Amides}

\section{1-1. ${ }^{1} \mathrm{H}$ NMR Spectrum of $\mathbf{3 a}$}

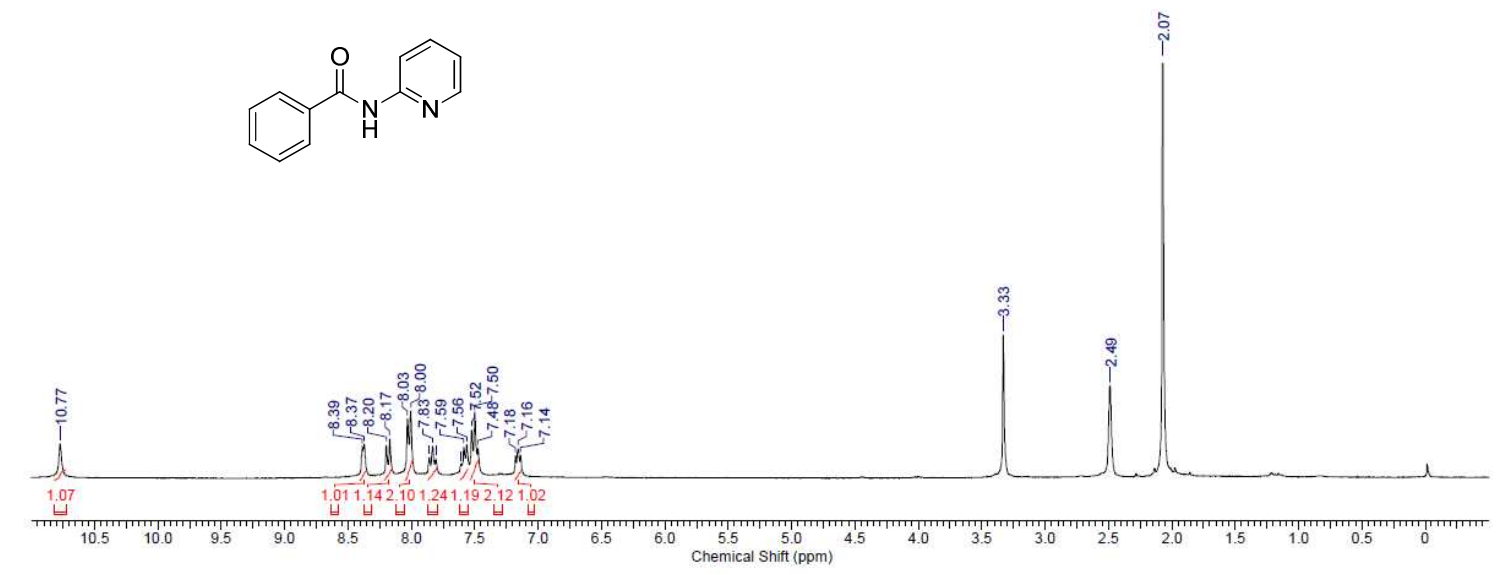

1-2. ${ }^{1} \mathrm{H}$ NMR Spectrum of $\mathbf{3 b}$

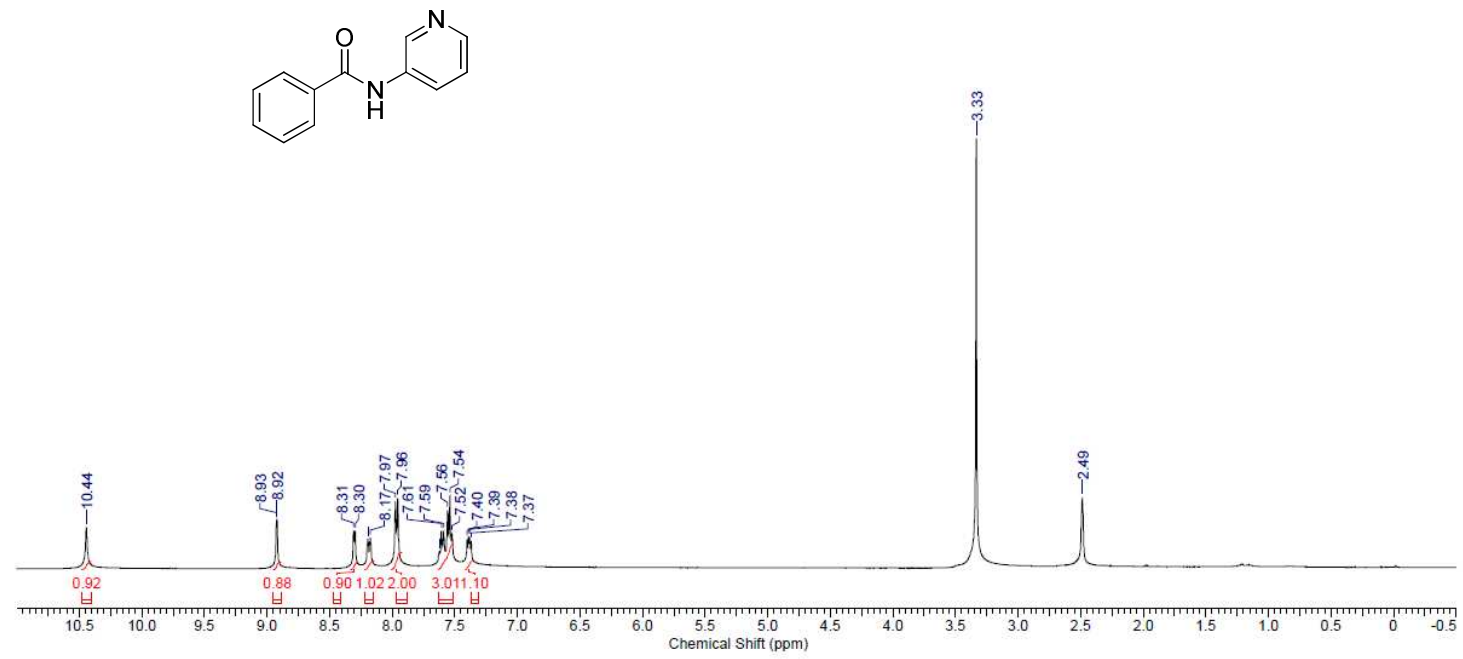




\section{1-3. ${ }^{1} \mathrm{H}$ NMR Spectrum of $\mathbf{5 a}$}

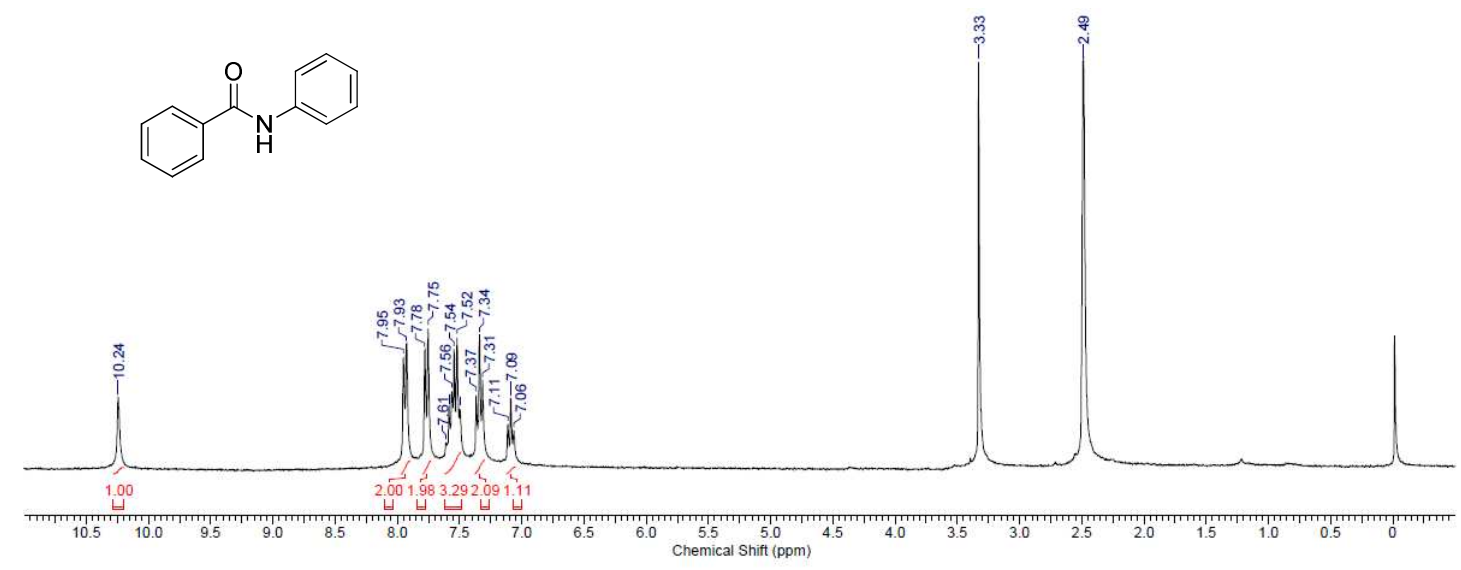

\section{1-4. ${ }^{1} \mathrm{H}$ NMR Spectrum of $\mathbf{5 b}$}

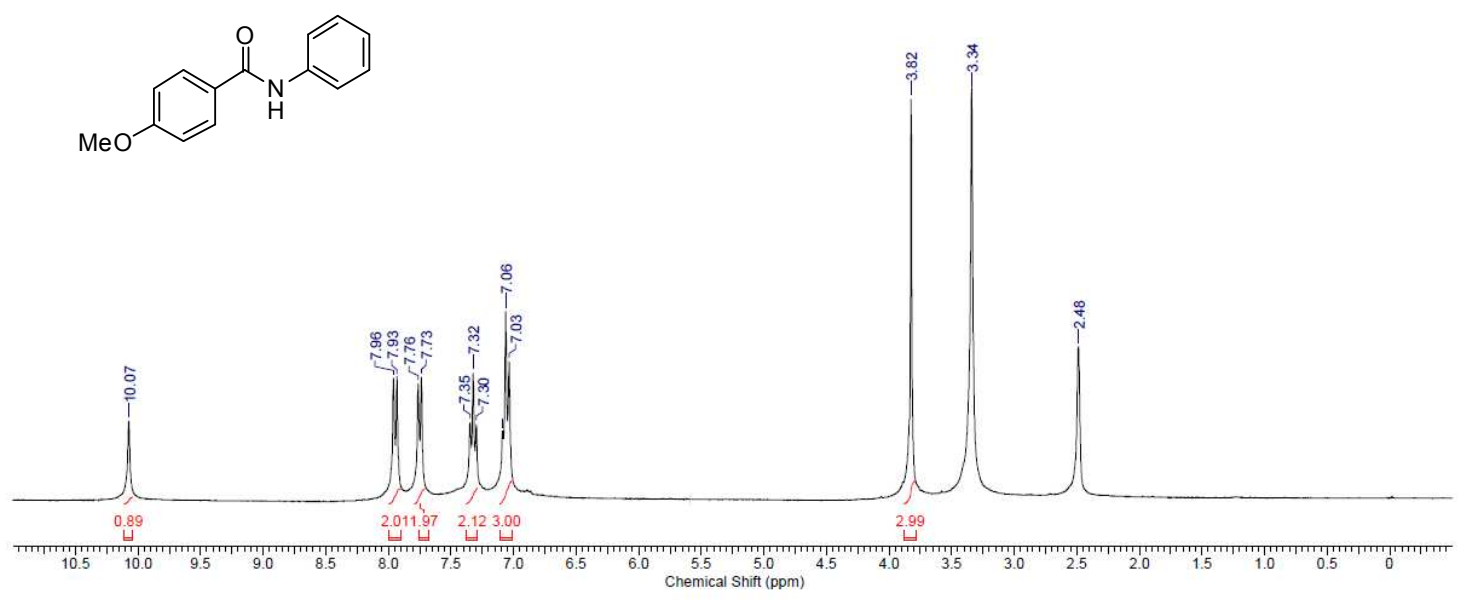




\section{1-5. ${ }^{1} \mathrm{H}$ NMR Spectrum of $\mathbf{5 c}$}

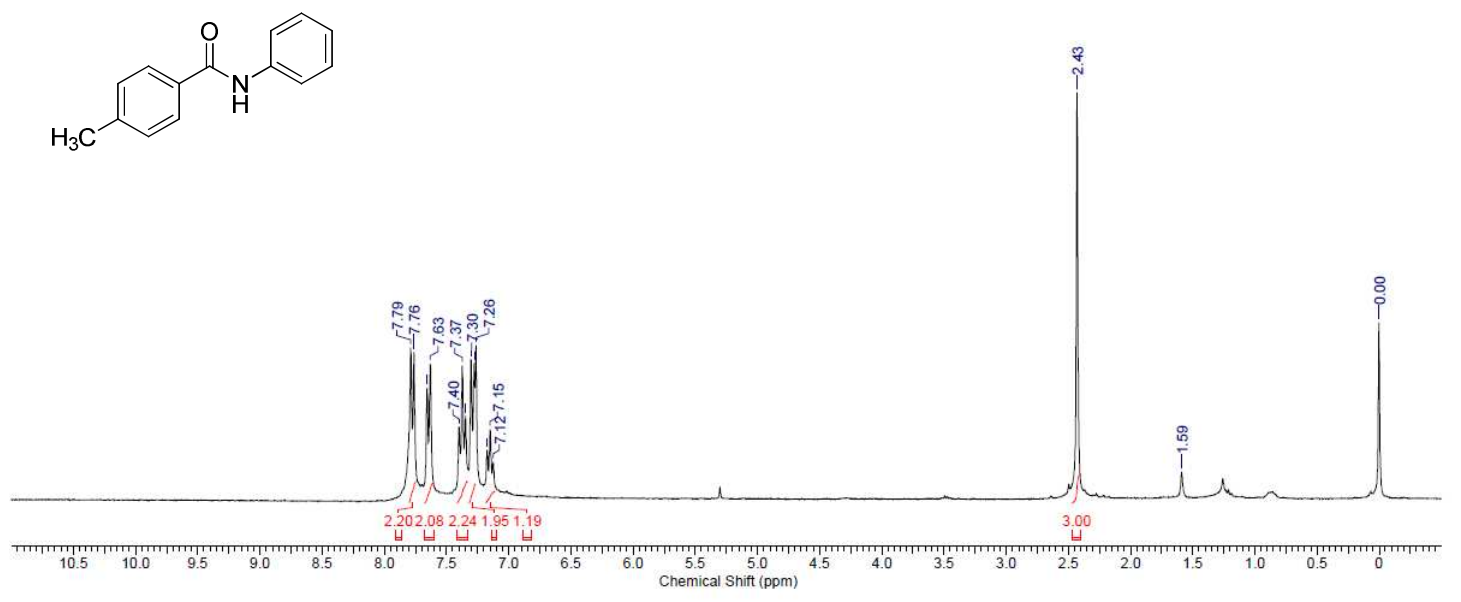

1-6. ${ }^{1} \mathrm{H}$ NMR Spectrum of $\mathbf{5 d}$

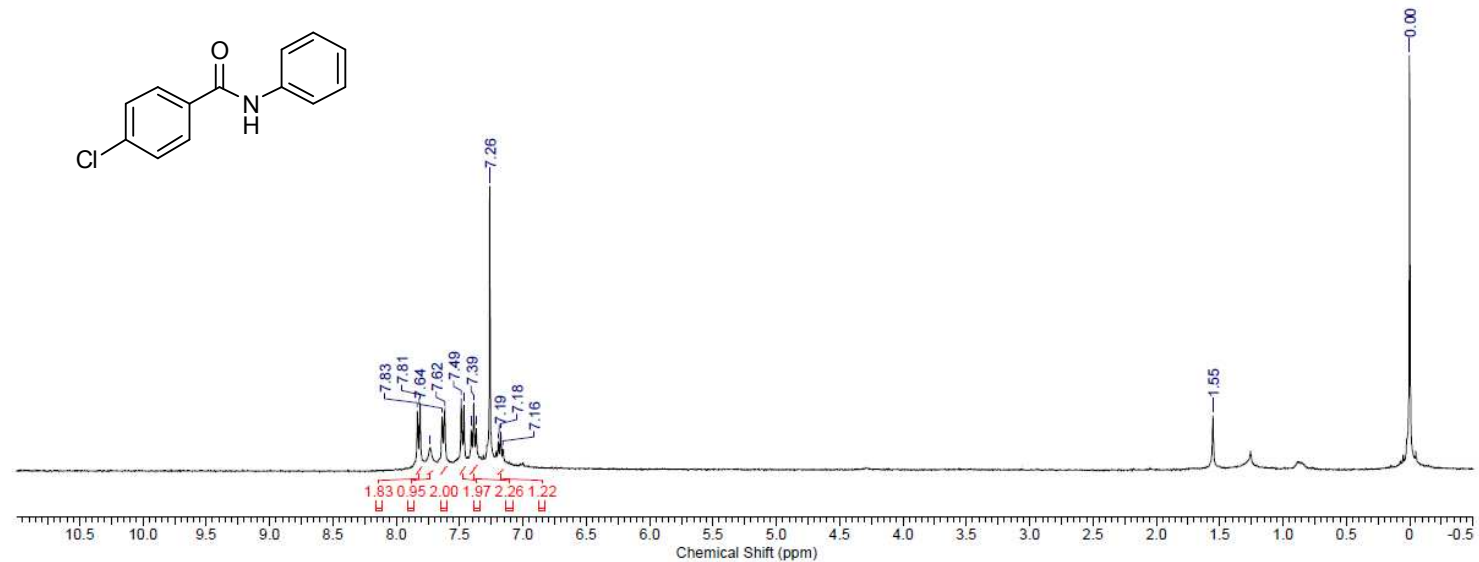




\section{1-7. ${ }^{1} \mathrm{H}$ NMR Spectrum of $\mathbf{5 e}$}

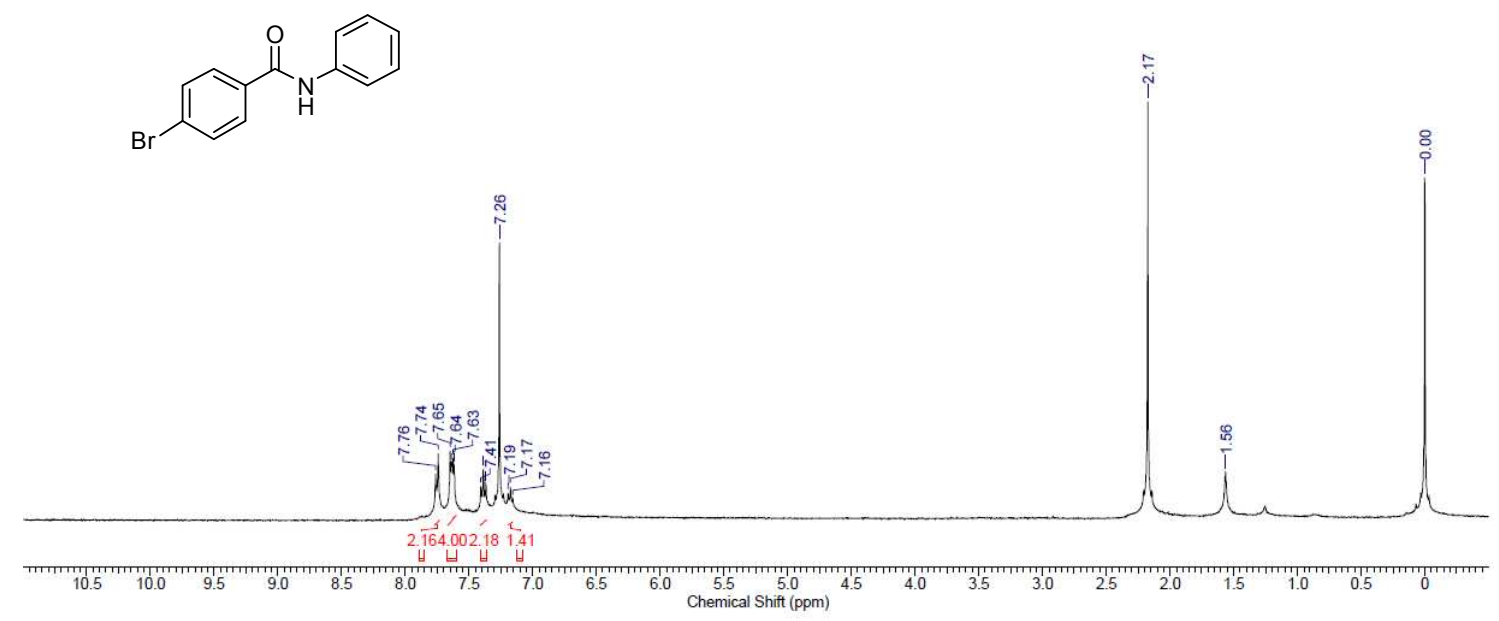

1-8. ${ }^{1}$ H NMR Spectrum of $\mathbf{5 f}$

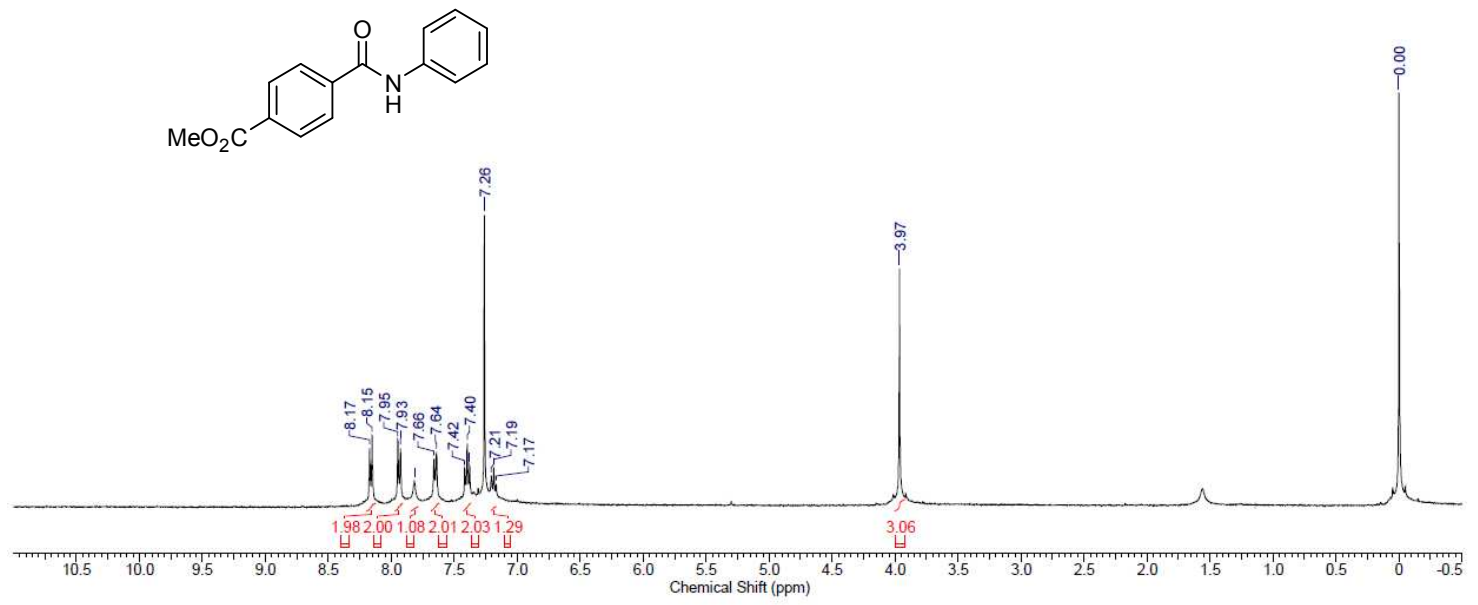




\section{1-9. ${ }^{1}$ H NMR Spectrum of $\mathbf{5 g}$}

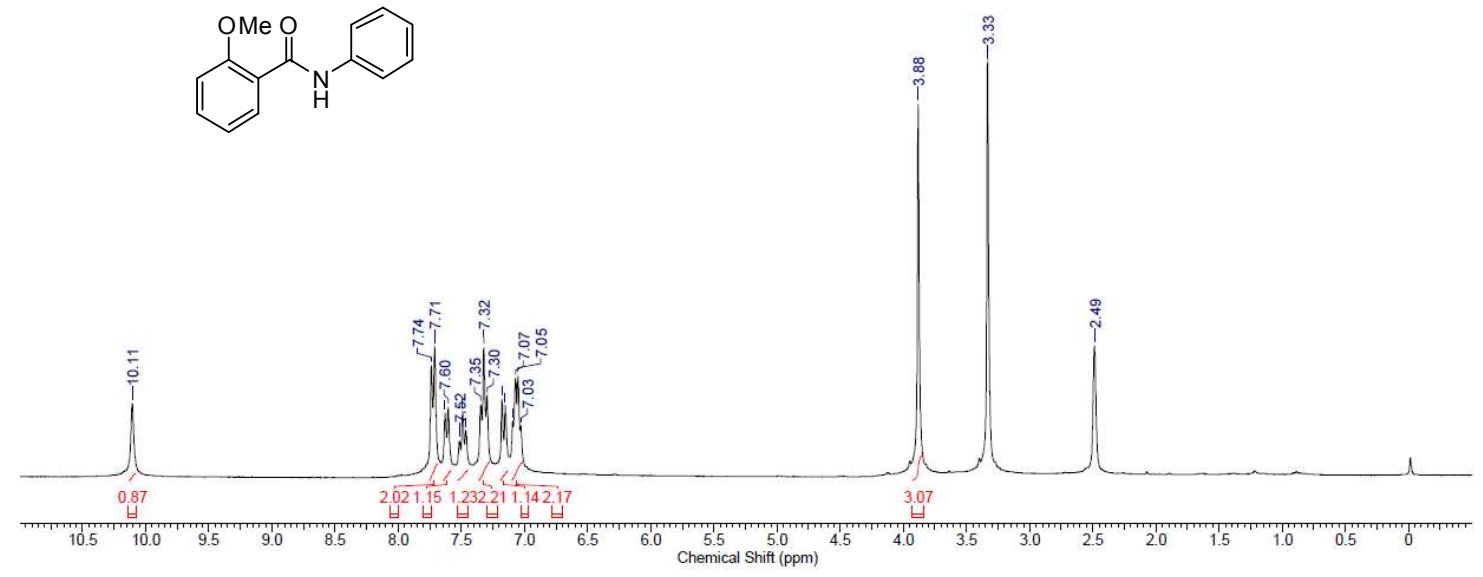

1-10. ${ }^{1}$ H NMR Spectrum of $\mathbf{5 h}$

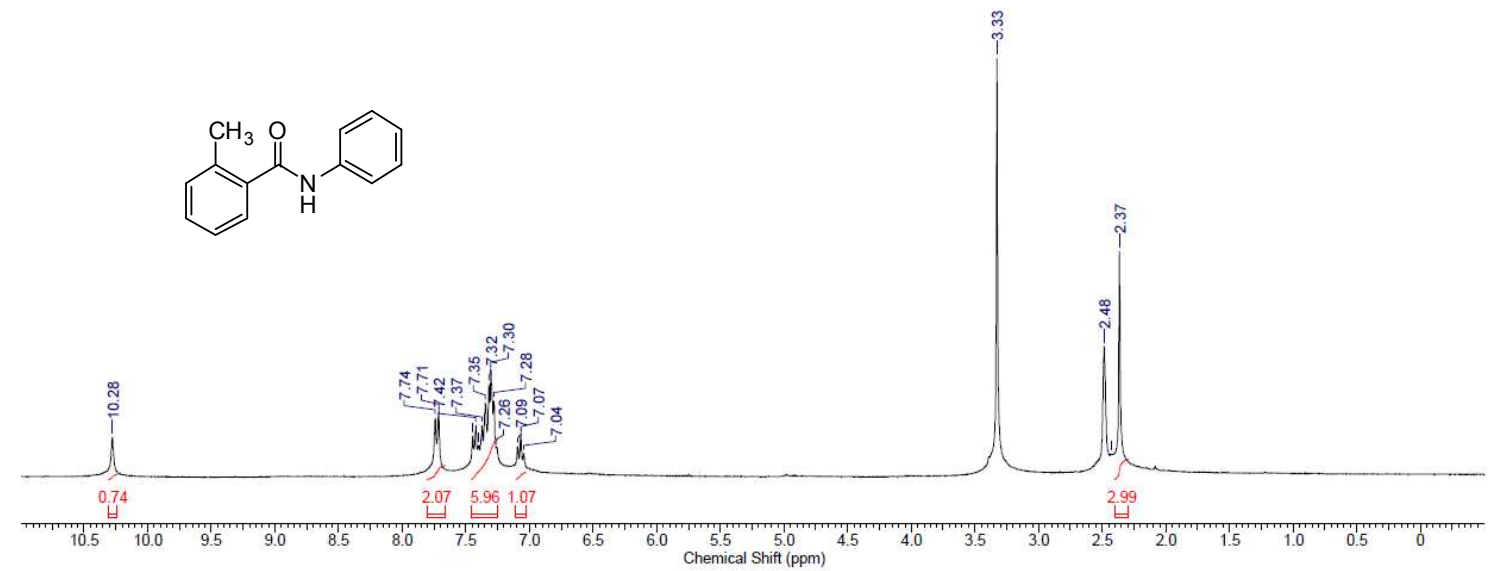




\section{1-11. ${ }^{1}$ H NMR Spectrum of $\mathbf{5 i}$}

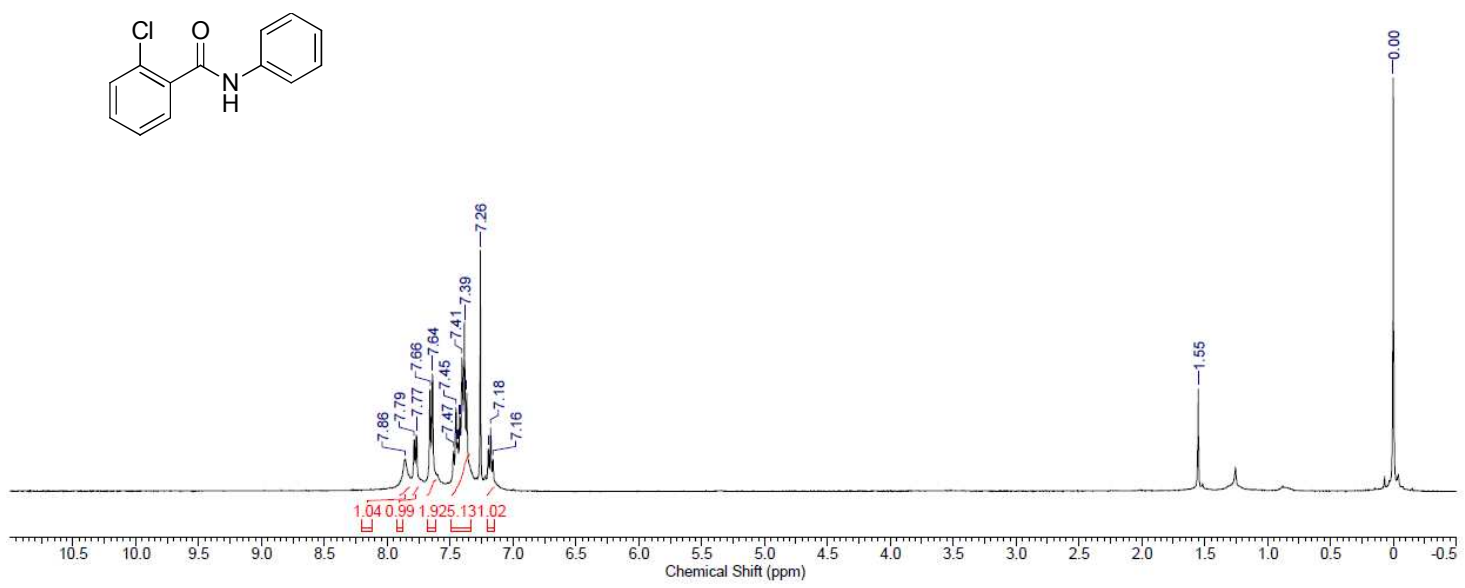

\section{1-12. ${ }^{1}$ H NMR Spectrum of $\mathbf{5 j}$}
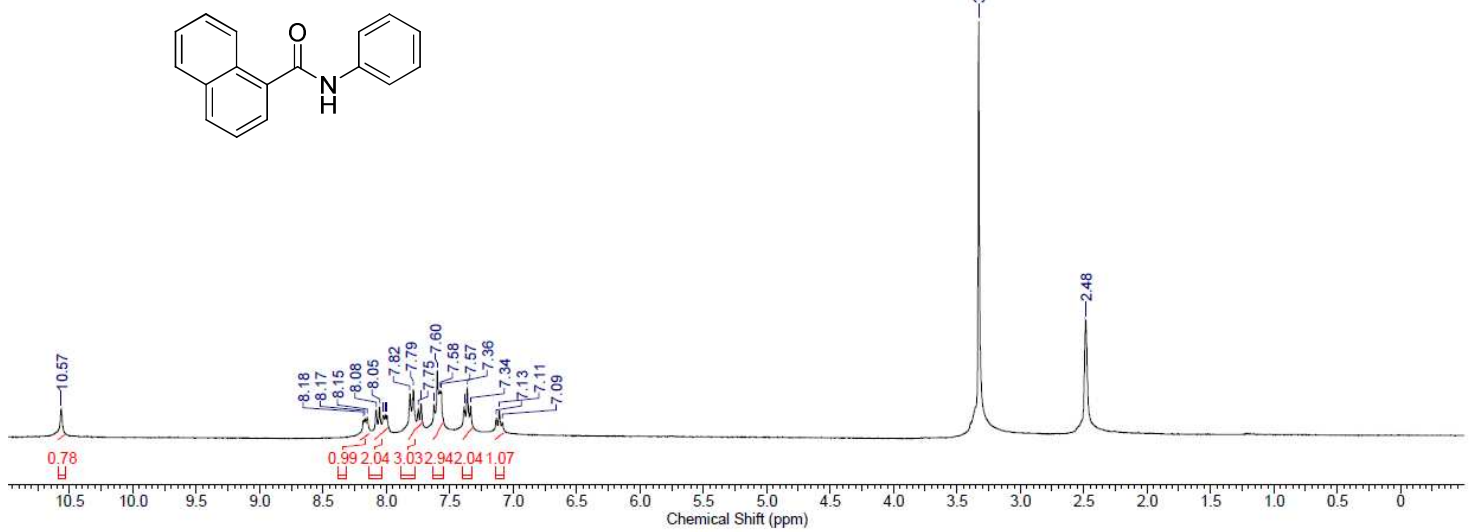


\section{1-13. ${ }^{1} \mathrm{H}$ NMR Spectrum of $\mathbf{5 k}$}
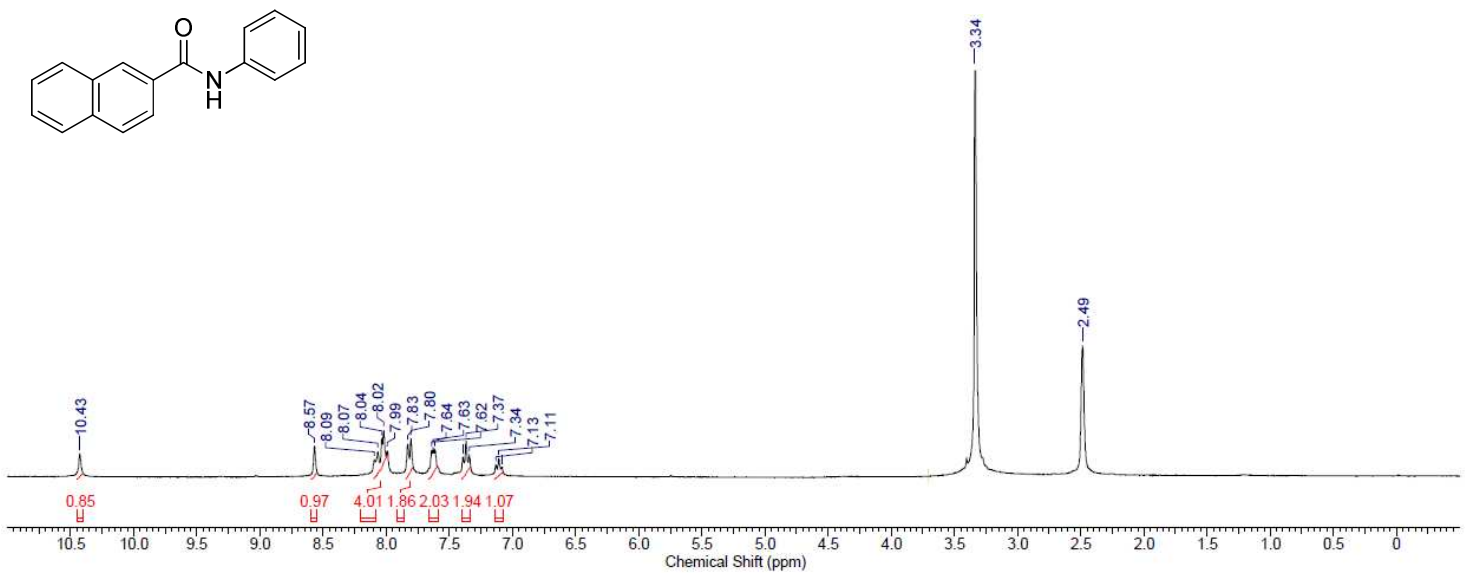

\section{1-14. ${ }^{1} \mathrm{H}$ NMR Spectrum of $\mathbf{5 l}$}
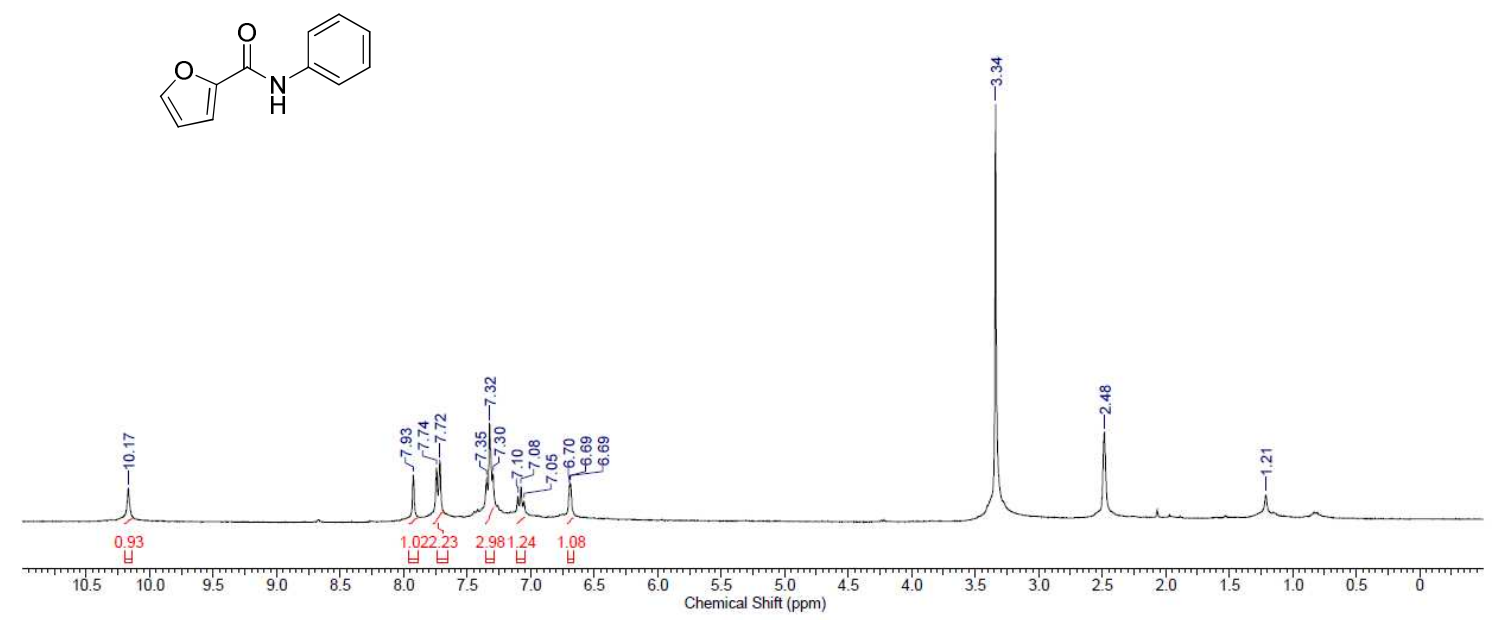


\section{1-15. ${ }^{1}$ H NMR Spectrum of $\mathbf{5 m}$}

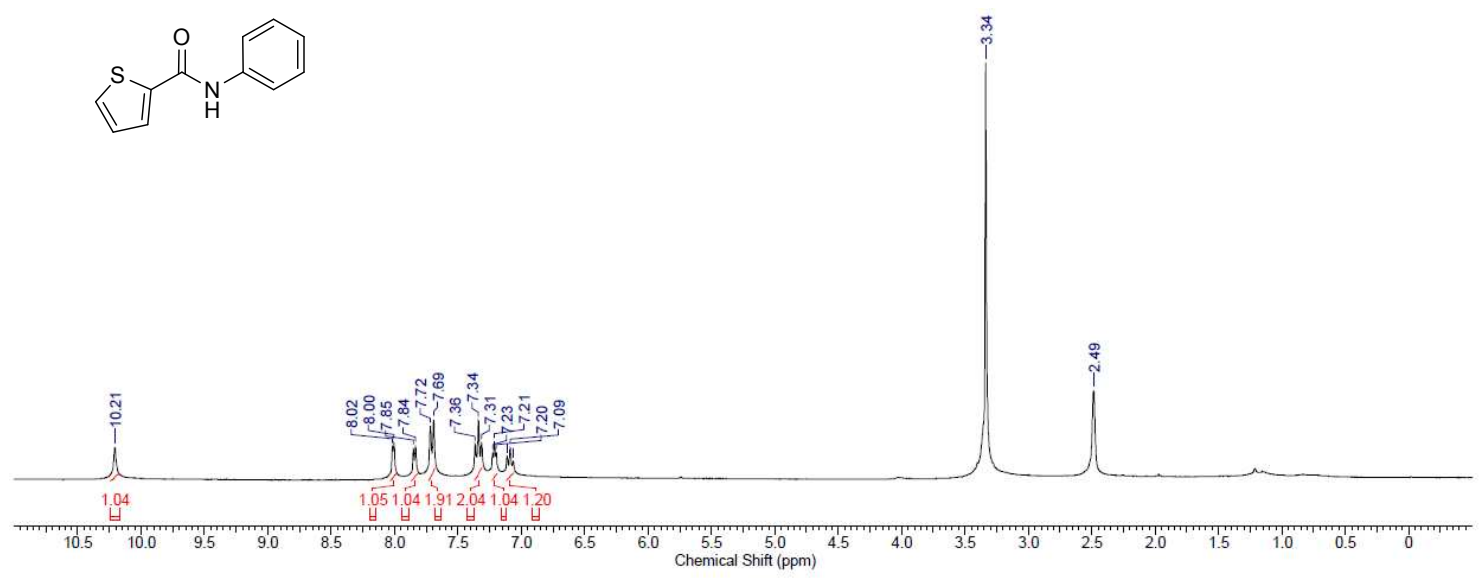

1-16. ${ }^{1}$ H NMR Spectrum of $\mathbf{5 n}$

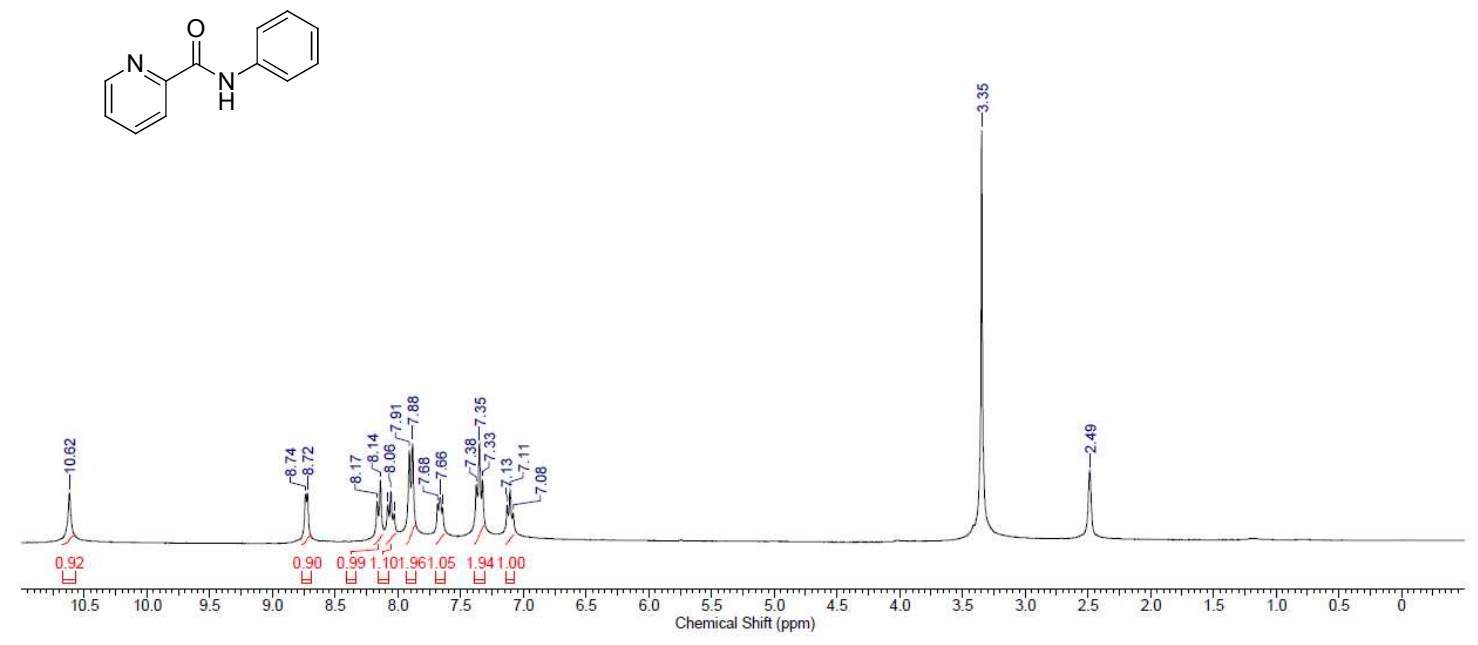




\section{1-17. ${ }^{1} \mathrm{H}$ NMR Spectrum of $\mathbf{5 0}$}

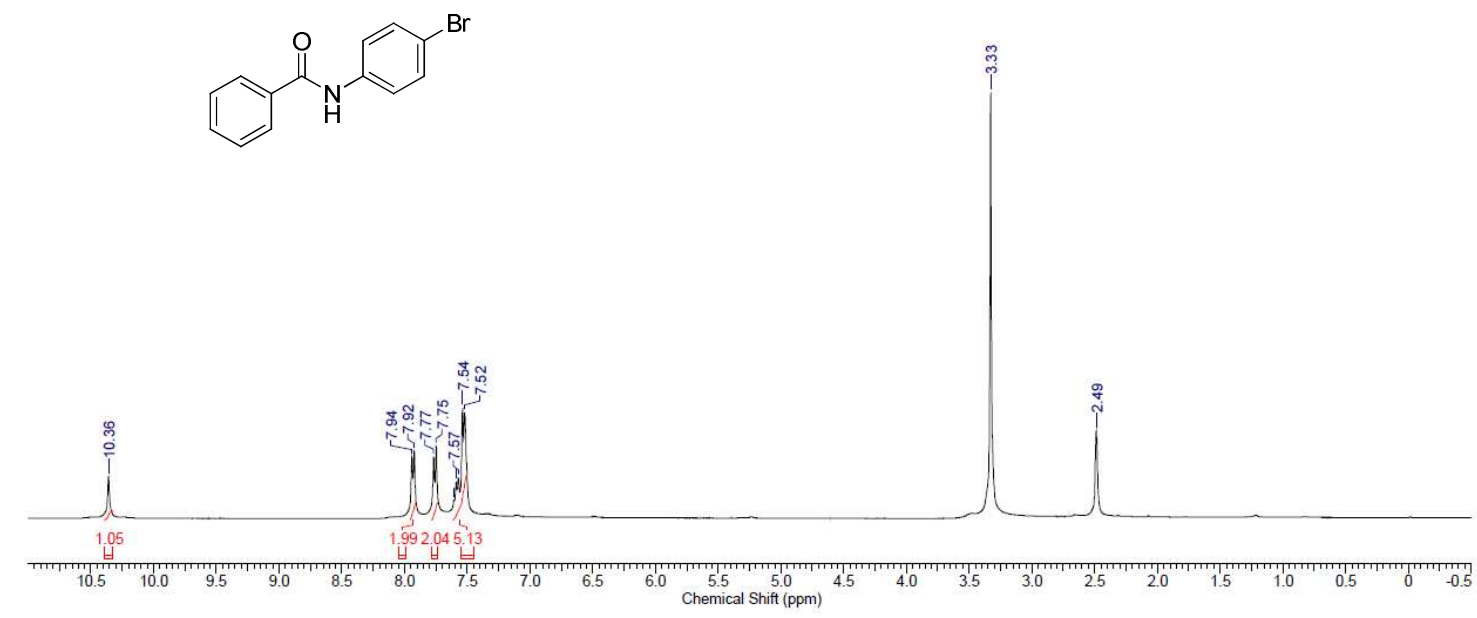

\section{1-18. ${ }^{1} \mathrm{H}$ NMR Spectrum of $\mathbf{5 p}$}

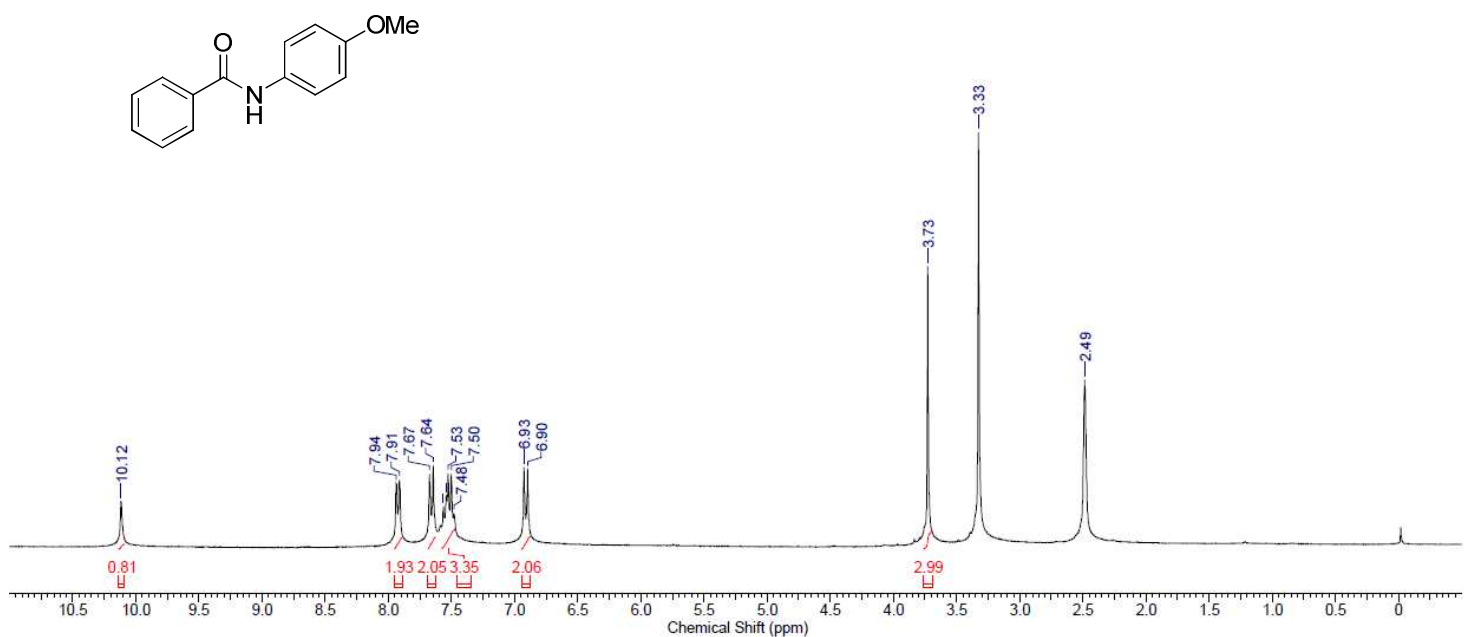


1-19. ${ }^{1}$ H NMR Spectrum of 11-H

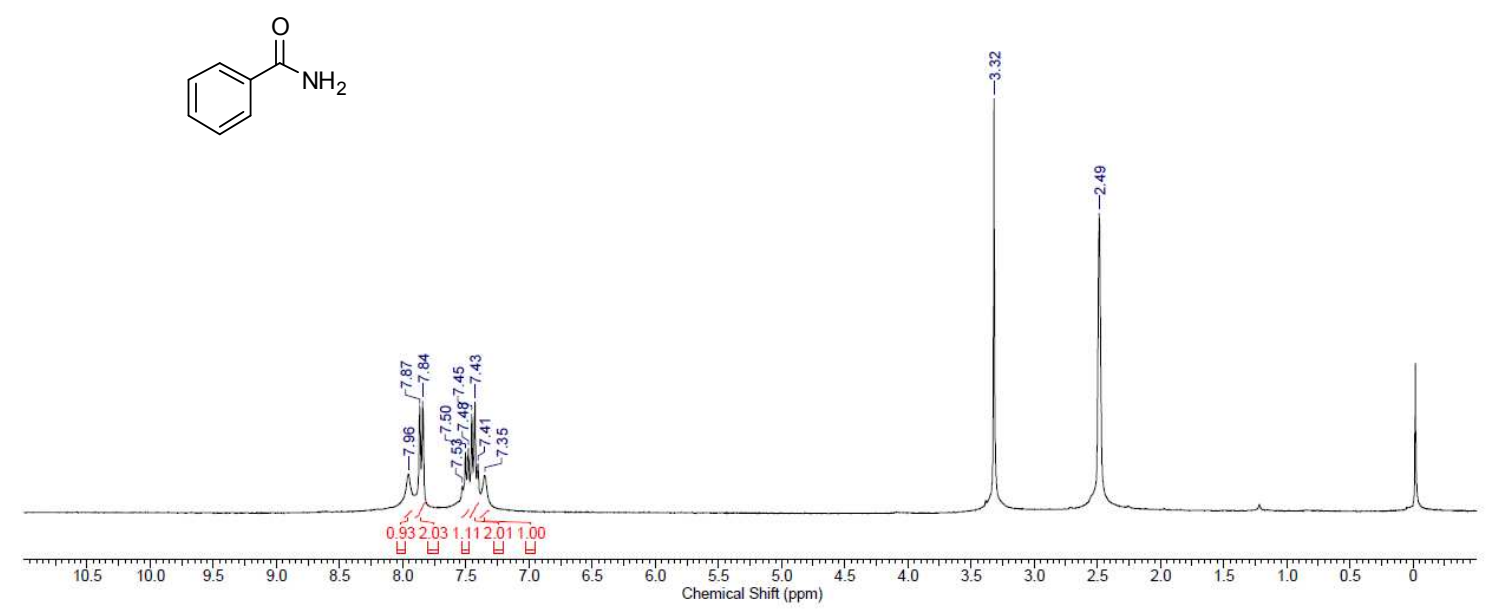

\section{1-20. ${ }^{1} \mathrm{H}$ NMR Spectrum of $\mathbf{1 1}$}

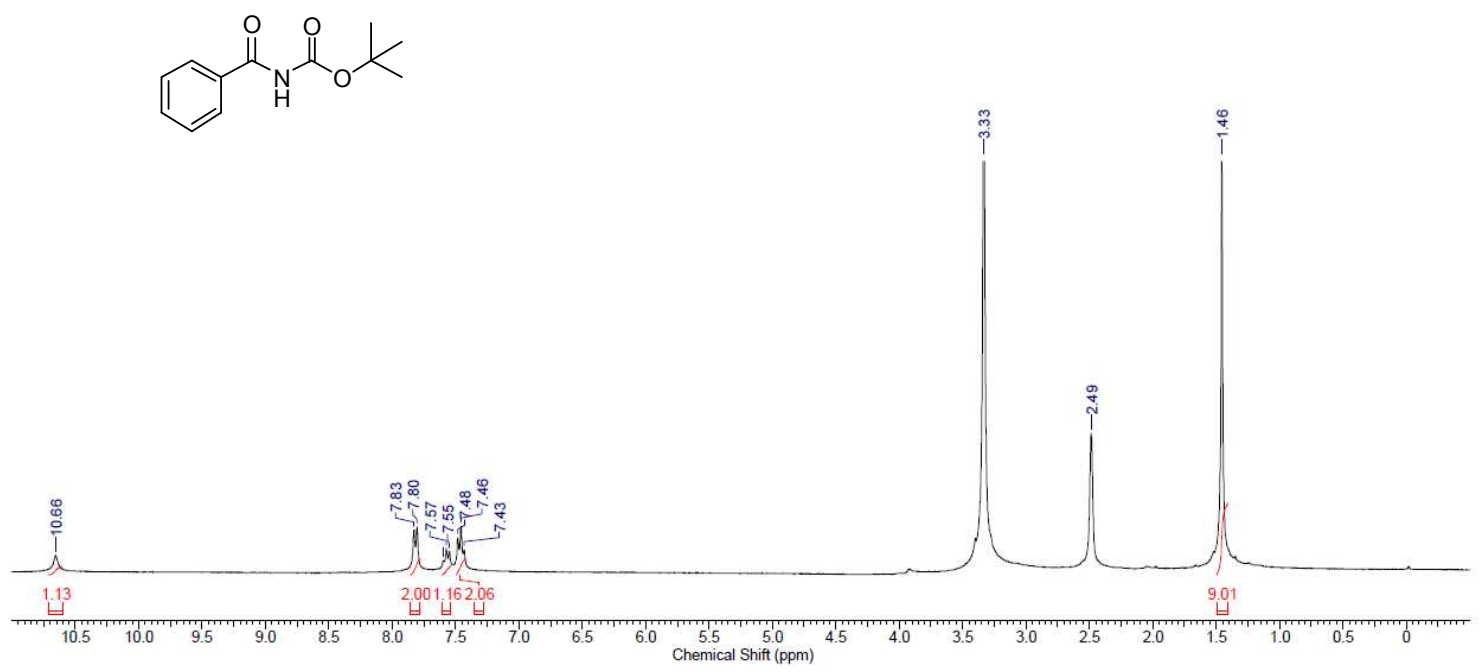




\section{1-21. ${ }^{1}$ H NMR Spectrum of $\mathbf{1 3}$}

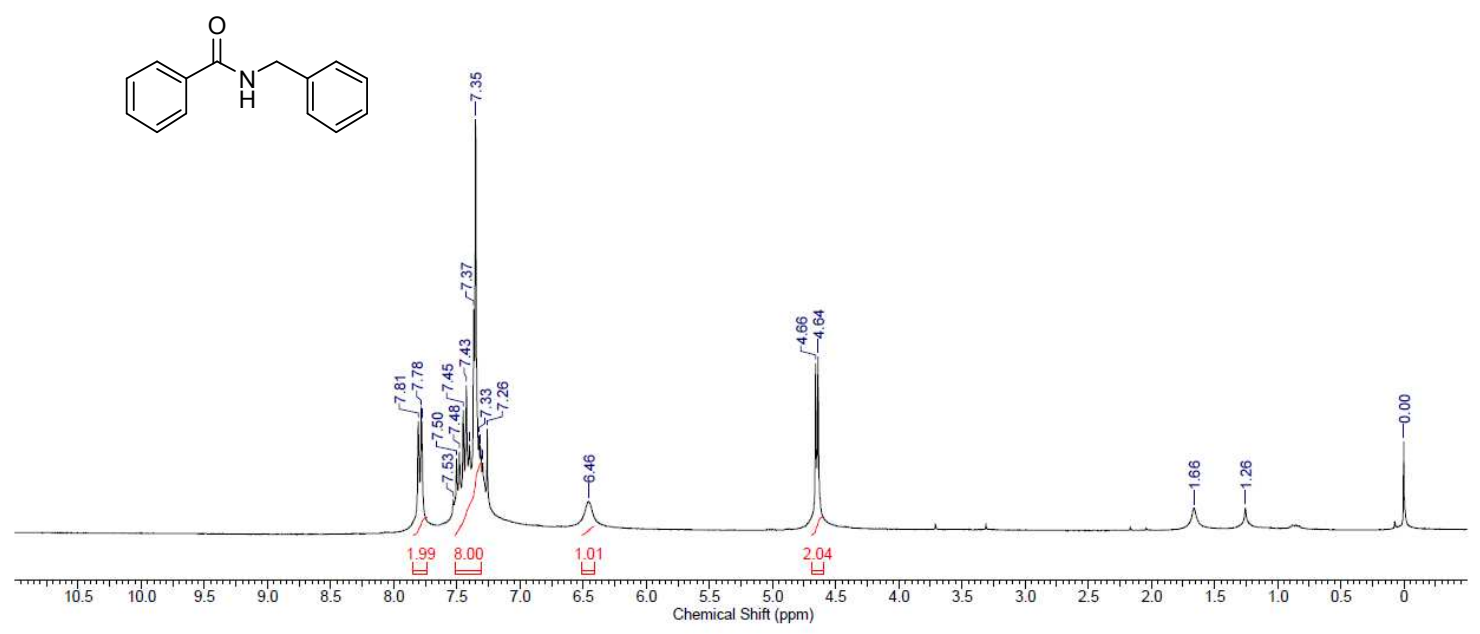

\section{1-22. ${ }^{1}$ H NMR Spectrum of $\mathbf{1 4}$}

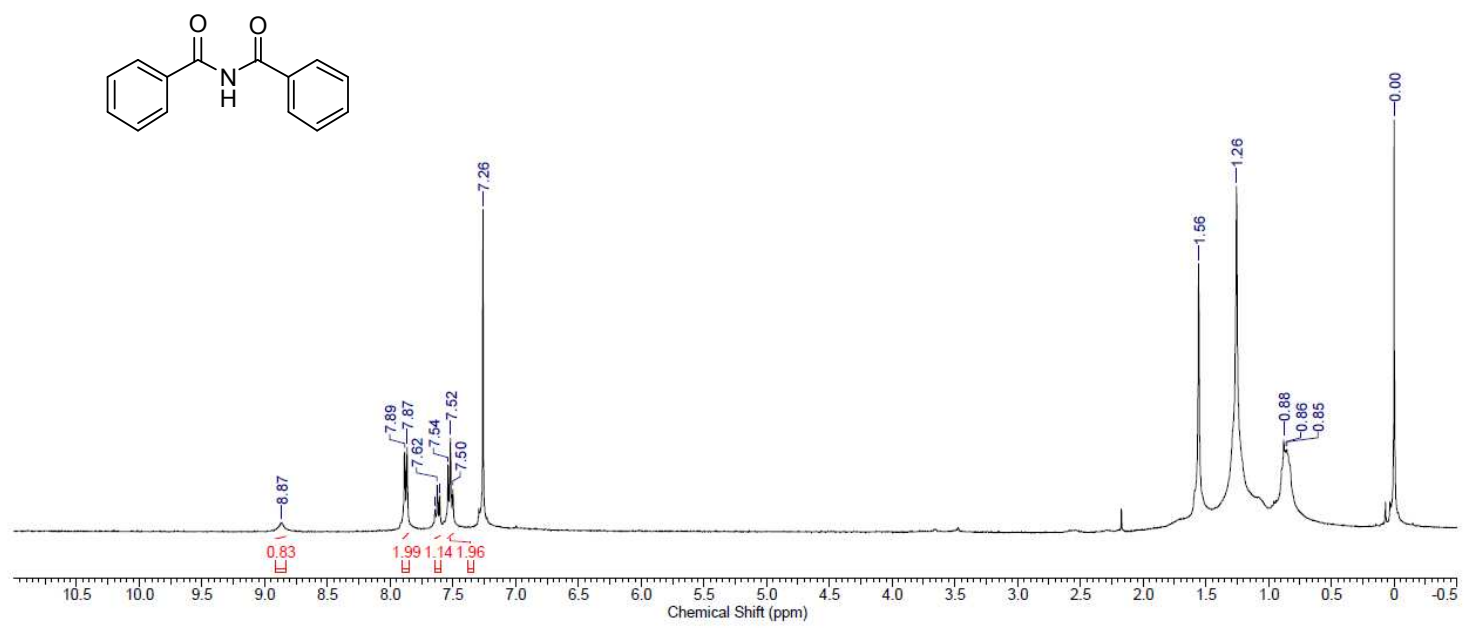

